International Journal of Biological Research, 3(1)(2015) 19-24
International Journal of Biological Research
SPC
Journal home page: www.sciencepubco.com/index.php/IJBR
doi: $10.14419 / i j b r . v 3 i 1.3546$
Research Paper

\title{
Effects of various local analgesics and ketamine for cranial epidural analgesia in Black Bengal Goats
}

\author{
Animesh Chandra Roy ${ }^{1 *}$, Md Rafiqul Islam ${ }^{2}$, Mohammed Kawser Hossain ${ }^{1}$, Nasrin Sultana Lucky ${ }^{1}$, \\ Md Rashedunnabi Akanda ${ }^{3}$, Bashudeb Paul ${ }^{4}$, Mir Md Iqbal Hasan ${ }^{5}$, \\ Md Shad Uddin Mahfuz ${ }^{6}$, Fokor Uddin ${ }^{7}$, Shipra Roy ${ }^{8}$ \\ ${ }^{1}$ Department of Surgery and Theriogenology, Sylhet Agricultural University, Sylhet \\ ${ }^{2}$ Department of Medicine, Sylhet Agricultural University, Sylhet \\ ${ }^{3}$ Department of Pharmacology and Toxicology, Sylhet Agricultural University, Sylhet \\ ${ }^{4}$ Department of Anatomy and Histology, Sylhet Agricultural University, Sylhet \\ ${ }^{5}$ Department of Physiology, Sylhet Agricultural University, Sylhet \\ ${ }^{6}$ Department of Animal Nutrition, Sylhet Agricultural University, Sylhet \\ ${ }^{7}$ Assistant Registrar, Advanced Studies Board, Sylhet Agricultural University, Sylhet \\ ${ }^{8}$ MS in Microbiology, Sylhet Agricultural University, Sylhet \\ *Corresponding author E-mail: animeshvet2009@gmail.com
}

\begin{abstract}
The present study was conducted to find out the effects of analgesic and anaesthetic drugs for cranial epidural analgesia in Black Bengal goats. A series of thirty two $(n=32)$ analgesic trails were conducted in goats age ranged from 8 to 12 months and with an average body weight of $8.1 \mathrm{~kg}$. The animals were divided into four groups $(\mathrm{n}=4)$ and a replication of 8 trails was performed in each group at least one week interval. Two percent (2\%) lidocaine hydrochloride $(6.0 \mathrm{mg} / \mathrm{kg}), 2 \%$ lidocaine hydrochloride with adrenaline $(6.0 \mathrm{mg} / \mathrm{kg}), 0.5 \%$ bupivacaine hydrochloride $(1.5 \mathrm{mg} / \mathrm{kg})$ and ketamine hydrochloride $(5.0 \mathrm{mg} / \mathrm{kg})$ were used to perform cranial epidural analgesia. $2 \%$ Lidocaine hydrochloride and Ketamine hydrochloride showed rapid onset of analgesia. $0.5 \%$ bupivacaine hydrochloride produced the highest area of desensitization in thigh region during cranial epidural analgesia. Perineal region and tail were totally desensitized during epidural analgesia. $0.5 \%$ bupivacaine hydrochloride prolonged the duration of analgesia during epidural analgesia. $2 \%$ Lidocaine hydrochloride showed no side effects whereas $2 \%$ Lidocaine hydrochloride with adrenaline showed straining and muscle tremor, $0.5 \%$ bupivacaine hydrochloride shivering and drowsiness, ketamine hydrochloride tympany, excitement and drowsiness. It seemed that $2 \%$ Lidocaine hydrochloride is more effective whereas $0.5 \%$ bupivacaine hydrochloride is associated with side effects. Though ketamine hydrochloride is a dissociative agent, it could also be used in epidural analgesia.
\end{abstract}

Keywords: Effect; Local Analgesics; Ketamine; Cranial Epidural Analgesia; Goats.

\section{Introduction}

Anaesthesia is one of the miracles of medicine, without which modern surgical techniques would have been impossible. It was first developed to alleviate pain and provide relaxation for surgery. It is employed in animals for a wide variety of operative interventions. The choice of different types of anaesthesia, use of anaesthetic and analgesic agents, route of administration of anaesthetic agents all are depended on the animals as well as patients. Sometimes, epidural analgesia is needed to perform major surgical operations for correction of goat diseases.

For correction of goat diseases, general anaesthesia often leads to tympanitis or regurgitation which is threatened for life Hasim and Hossain (1989). Epidural anaesthesia was first reported in dogs by Cathelin in 1901, but due to the larger anaesthetic requirement and to the toxicity of cocaine, it was not used until 1921, Lumb and Jones (1984). The drug so injected, temporarily paralyses the spinal nerve roots, its contacts, resulting in analgesia of tissues innervated by the nerves Booth (1988). It is classified according to the site at which the injection is made, i.e. Cranial (high) and Caudal (low). The use of epidural analgesia in veterinary medicine is most common in large animal practice. The method is also frequently used in small animals.

The local analgesic agents vary in their potency, duration of action and cost. Lignocaine is an amide type local analgesic and has a relatively rapid onset of action and an intermediate duration of about 1 to 2 hours, Carpenter et al. (2004). Bupivacaine is a long acting local analgesic. It is about 4 times more potent than lignocaine and is used most commonly for regional and epidural nerve block, Eugene and Nicholas (1995). The effect of a local analgesic is increased by addition of vasoconstrictor agents. Addition of adrenaline is a common practice for prolongation of the action of local analgesic drugs, Lumb and Jones, (1984). These drugs indiscriminately block the sensory, sympathetic and motor fibers, Dripps et al, (1988). Ketamine hydrochloride, a dissociative agent has been used epidurally to relieve pre and post-operative pain in both man and animals. Spontaneous, unprovoked movements may occasionally be occurred in deeply anaesthetized patients, Brander et al. (1991). 


\section{Materials and methods}

The proposed research work was conducted in 8 goats (Capra hircus). These animals were apparently healthy especially during the experiment. The body weight of these animals ranged from 7.5 $\mathrm{kg}$ to $8.6 \mathrm{~kg}$ and their ages ranged from 8 months to 1 year. They were of both sexes. A total of 32 experimental trails were performed in these animals to investigate the effect of certain local anaesthetics in cranial (Lumbo-sacral) epidural space. The work was carried out in the operation theatre of the veterinary clinics, Sylhet Agricultural University, Sylhet-3100. The period of experiment was 1 (one) year starting from March 2011 to March 2012.

\subsection{Management of experimental animals}

The animals were maintained in a room at the veterinary clinic of Sylhet Agricultural University, Sylhet collected from Sylhet Govt. goat farm. The animals were kept under good hygienic condition. They were allowed to graze in the open field for 6 hours every day and had a free access to water adlibitum. Standard concentrate feed was supplied. All animals were routinely dewormed and vaccinated against common infectious diseases. The animals were frequently examined to detect any pathological condition.

\subsection{Preparation of the animals}

The goats were taken to the operation theatre 20 to 30 minutes prior to administration of analgesic or anaesthetic agents. Age, sex and body weight were recorded before starting the experiment. The body weight of each of the animals was taken by using weighing machine. The animals were then examined clinically to detect any pathological condition. The animals were placed on the operation table in lateral recumbency and were restrained physically by an assistant and also casting by ropes. The injection site was clipped, shaved and painted with tincture of iodine before any injection was administered. No premedicant was given prior to anaesthetic injection. The analgesia was always performed in the morning throughout the course of investigation.

\subsection{Anaesthetic agents}

\subsubsection{2\% Lignocaine hydrochloride}

Lignocaine hydrochloride (Jasocaine ${ }^{\circledR}$, Jayson Pharmaceuticals Ltd.) is one of the most versatile and widely used local analgesic agents which are available in Bangladesh in $50 \mathrm{ml}$ vial. Each milliliter contains $20 \mathrm{mg}$ Lidocaine HCL (anhydd.).

\subsection{2. $2 \%$ Lignocaine hydrochloride with $0.0005 \%$ adrenaline}

$2 \%$ Lignocaine hydrochloride with $0.0005 \%$ adrenaline (Jasocaine $A \circledast$, Jayson Pharmaceuticals Ltd.) is available in Bangladesh in 50 $\mathrm{ml}$ vial. Each milliliter contains $20 \mathrm{mg}$ Lidocaine and $5 \mu \mathrm{g}$ adrenaline.

\subsubsection{5\% Bupivacaine hydrochloride}

Bupivacaine hydrochloride (Ultracaine ${ }^{\circledR}$, Jayson Pharmaceuticals Ltd.) is an amide type local analgesic available in Bangladesh in $30 \mathrm{ml}$ vial. Each milliliter contains $5 \mathrm{mg}$ Bupivacaine hydrochloride (anhydrous)

\subsubsection{Ketamine hydrochloride (a dissociative anaesthetic agent)}

Ketamine hydrochloride (G-KETAMINE®, Gonoshasthaya Pharmaceuticals Ltd., and Dhaka) is available in Bangladesh in 10 $\mathrm{ml}$ vial. Each milliliter conatins $50 \mathrm{mg}$ ketamine.

\subsection{Methods of cranial epidural analgesia}

The goats were restrained on the operating table in lateral recumbency, the back was flexed and the hind limbs were held forward. The site of injection was immediately posterior to the last lumbar spine. The site of injection was clipped, cleaned and disinfected. A 3 inch, 18 gauge needle was inserted at the lumbo-sacral space and the analgesic solution was injected.

\subsection{Experimental design (Table 1)}

In this experiment a complete randomized design was used. The animals were divided into 4 (four) different groups. In each group 8 (eight) experimental trials were accomplished. To mitigate possible development of resistance to anaesthetic agents, a replication of the trails was made at least one week interval. Studies in these goats were carried out in the absence of surgical stress.

Table 1: Experimental Design

\begin{tabular}{|c|c|c|c|c|}
\hline Groups & $\begin{array}{l}\text { Types of } \\
\text { analgesia }\end{array}$ & $\begin{array}{l}\text { No. } \\
\text { of } \\
\text { trails }\end{array}$ & $\begin{array}{l}\text { Site of } \\
\text { injection }\end{array}$ & $\begin{array}{l}\text { Concentration and doses } \\
\text { of drugs }\end{array}$ \\
\hline A & $\begin{array}{l}\text { Cranial } \\
\text { epidural }\end{array}$ & 8 & $\begin{array}{l}\text { Lumbo- } \\
\text { sacral }\end{array}$ & 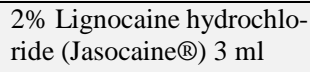 \\
\hline B & $\begin{array}{l}\text { Cranial } \\
\text { epidural }\end{array}$ & 8 & $\begin{array}{l}\text { Lumbo- } \\
\text { sacral }\end{array}$ & $\begin{array}{l}2 \% \text { Lignocaine hydrochlo- } \\
\text { ride with } 0.0005 \% \text { adrena- } \\
\text { line (Jasocaine } A ®)) 3 \mathrm{ml}\end{array}$ \\
\hline $\mathrm{C}$ & $\begin{array}{l}\text { Cranial } \\
\text { epidural }\end{array}$ & 8 & $\begin{array}{l}\text { Lumbo- } \\
\text { sacral }\end{array}$ & 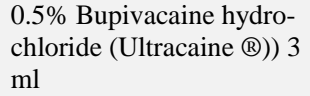 \\
\hline D & $\begin{array}{l}\text { Cranial } \\
\text { epidural }\end{array}$ & 8 & $\begin{array}{l}\text { Lumbo- } \\
\text { sacral }\end{array}$ & $\begin{array}{l}\text { Ketamine hydrochloride } \\
\text { (G-KETAMINE®) } 1 \mathrm{ml}\end{array}$ \\
\hline
\end{tabular}

\subsection{Analgesic assessment}

All animals were maintained on standing position during analgesic assessment. The state of analgesia was observed in every 5 minute with the help of a needle, by pricking the region. Analgesia was assessed as " $+++"$ excellent (no response), "++" adequate (slight movement or reflex response), "+" poor (avoidance response) to needle pricking. Onset, peak point (time at which maximum area was desensitized) and the duration of analgesia were recorded. The desensitized area was measured by a scale and the progressions of analgesia at every 5 minutes were recorded. The measurement was carried out up to recovery. Tail movement, leg movement and any side effects were closely observed and recorded during the course of analgesia. Care was taken not to excite the animal before and during monitoring

\subsection{Statistical analysis}

The data were analyzed statistically as follows

The mean of data with its standard deviation (SD) was calculated. The results were analyzed by the Least Significant Difference test in "MSTAT" software.

\section{Results}

\subsection{The onset of analgesia during cranial epidural anal- gesia}

The onset of anaesthesia occurred within 1-8 minutes in all animals of Group A and the mean value of onset was $4.0 \pm 2.27 \mathrm{~min}$. In Group B, the mean value of onset was $5.88 \pm 1.89$ min and onset occurred within 3-8 min. In Group C, the onset of anaesthesia occurred within 7-12 min and the mean value was $9.38 \pm 1.68 \mathrm{~min}$. The mean value of onset was $3.88 \pm 1.41 \mathrm{~min}$ in Group D. Onset occurred within 2-6 min in all animals of Group D. There were not significant $(\mathrm{P}>0.05)$ variations between Group A and D. Besides these there were statistically significant $(\mathrm{P}<0.01)$ variations between different groups in term of onset of anaesthesia. The onset of anaesthesia was significantly highest in Group C compared to other groups. (Table 2) 


\subsection{The peak point of analgesia during cranial epidural} analgesia

Anaesthesia reached peak point within 5-12 minutes in all animals of Group A and the mean value was $8.38 \pm 2.45 \mathrm{~min}$. In Group B, the mean value was $9.63 \pm 2.73 \mathrm{~min}$ and the anaesthetic agent exerted its maximum effect within 5-15 min in all animals. In Group
$\mathrm{C}$, the peak point of anaesthesia was within 10-20 min and the mean value was $15.5 \pm 3.27 \mathrm{~min}$. The mean value was $7.13 \pm 1.80$ min in Group D and anaesthesia reaches peak point within 5-10 min.

There was statistically significant $(\mathrm{P}<0.01)$ variations between different groups in term of extent of anaesthesia. The peak point of anaesthesia was significantly highest in Group C. (Table 2).

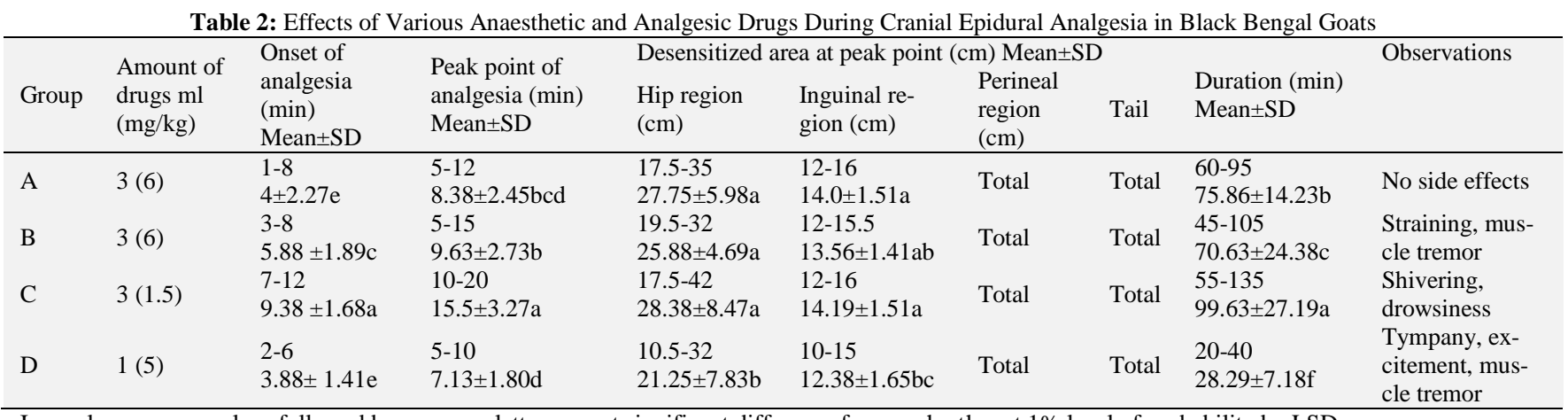

In a column, mean values followed by common letter are not significant difference from each other at $1 \%$ level of probability by LSD
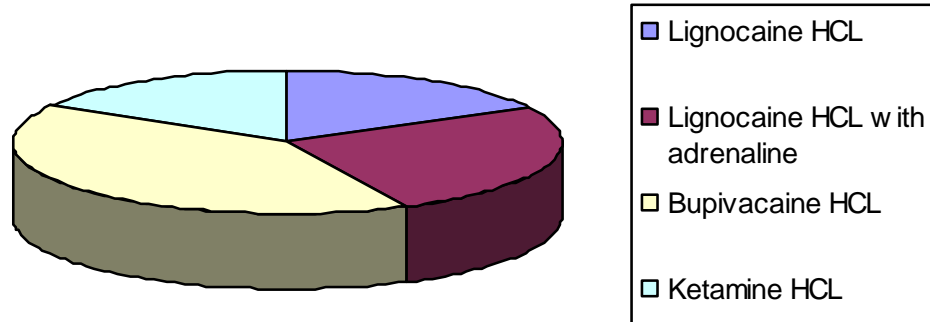

Onset of analgesia

Fig. 1: Comparison between the onset time of analgesia after cranial epidural administration of Lignocaine HCL, Lignocaine HCL with adrenaline, Bupivacaine HCL, Ketamine HCL.
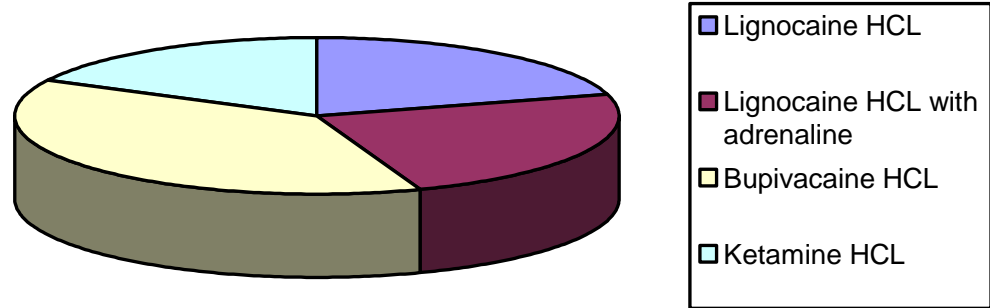

Peak time of analgesia

Fig. 2: Comparison between the peak point of analgesia after cranial epidural administration of Lignocaine HCL, Lignocaine HCL with adrenaline, Bupivacaine HCL, Ketamine HCL.
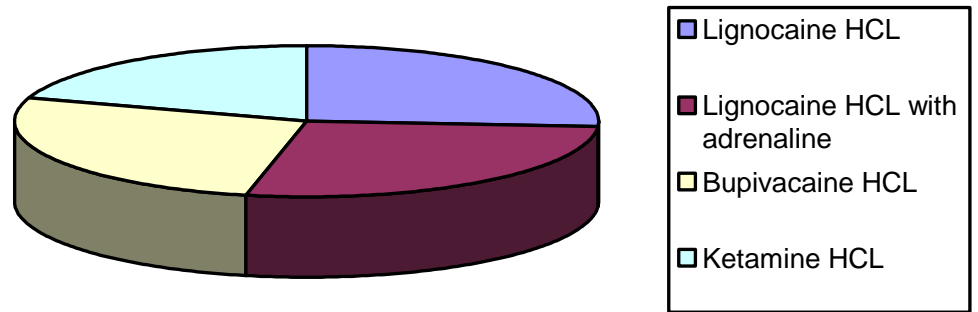

Area of desensitization in hip region

Fig. 3: Comparison between area of desensitization in hip region at peak point of analgesia after cranial epidural administration of Lignocaine HCL, Lignocaine HCL with adrenaline, Bupivacaine HCL, Ketamine HCL. 

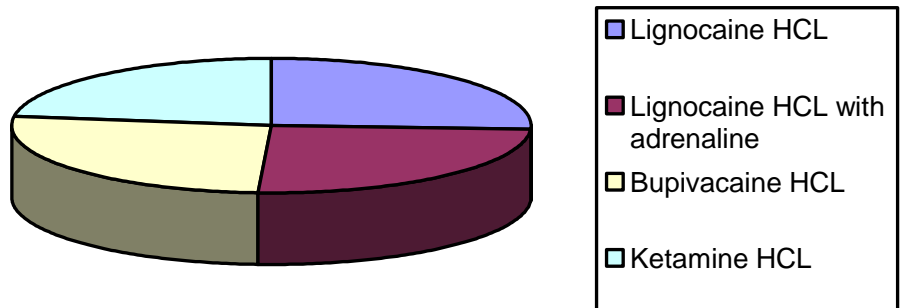

Area of desensitization in inguinal region

Fig. 4: Comparison between area of desensitization in inguinal region at peak point of analgesia after cranial epidural administration of Lignocaine HCL, Lignocaine HCL with adrenaline, Bupivacaine HCL, Ketamine HCL.
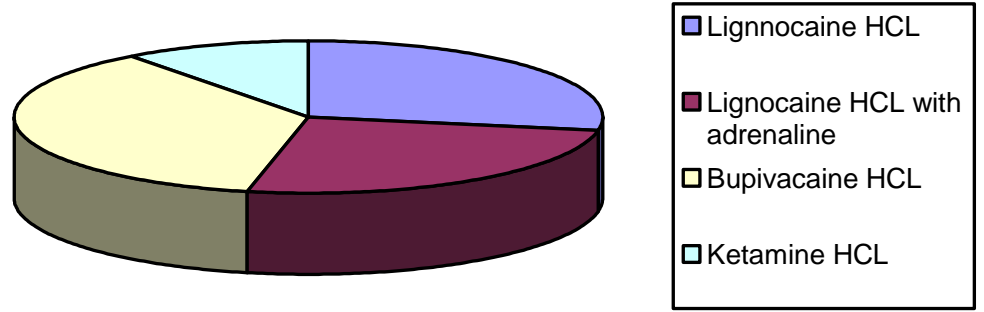

Duration

Fig. 5: Comparison between duration time of analgsia after cranial epidural administration of Lignocaine HCL, Lignocaine HCL with adrenaline, Bupivacaine HCL, Ketamine HCL.

\subsection{The extent of analgesia}

\subsubsection{Area of desensitization in hip region}

The mean distance traversed by the anaesthetic agent in Group A was $27.75 \pm 5.98 \mathrm{~cm}$, in Group B $25.88 \pm 4.69 \mathrm{~cm}$, in Group C $28.38 \pm 8.47 \mathrm{~cm}$, in Group D $21.25 \pm 7.83 \mathrm{~cm}$. There was not significant variation among Groups A, B \&C. Otherewise, there was statistically significant difference among various groups in term of area of desensitization in hip region. The area of desensitization in hip region was significantly higher in Group A, B \& C. (Table 2)

\subsubsection{Area of desensitization in inguinal region}

The area of desensitization in Group A was $14.0 \pm 1.51 \mathrm{~cm}$, in Group B $13.56 \pm 1.41 \mathrm{~cm}$, in Group C $14.19 \pm 1.51 \mathrm{~cm}$, in Group D $12.38 \pm 1.65 \mathrm{~cm}$. There was not significant variation between Groups a \& C. Otherwise, there was statistically significant difference among various groups in term of area of desensitization in inguinal region. The area of desensitization in inguinal region was significantly higher in Group a \& C. (Table 2)

\subsubsection{Area of desensitization in perineal region and tail}

In epidural analgesia the area of desensitization from the site of injection to the perineal region upto tail was total in all animals Similarly, the full length of tail was anaesthesized in all animals So, there was no significant difference among them. (Table 2)

\subsection{The duration of analgesia}

The mean value of duration was $75.86 \pm 14.23 \mathrm{~min}(60-95 \mathrm{~min})$ in Group A. The mean value of duration was $70.63 \pm 24.3$ min (45105 min) in Group B. In Group C the duration of analgesia was in between $55-135 \mathrm{~min}$ and the mean value was $99.63 \pm 27.19 \mathrm{~min}$. In Group D, the mean value of rueation of anaesthesia was $28.29 \pm 7.18 \mathrm{~min}$ and duration was in between $20-40 \mathrm{~min}$. These differences were statistically significant $(\mathrm{P}<0.01)$. The duration of anaesthesia was highest in Group C compared to other groups.

There were statistically significant $(\mathrm{P}<0.01)$ variations among different groups in term of duration of anaesthesia.The duration of anaesthesia was largest in Group C compared to other groups. (Table 2)

\subsection{Other observations}

Straining and muscle tremor were found in Group B after using Lignocaine HCL with adrenaline. Shivering and drowsiness were present in Group C after using Bupivacaine HCL. Tympany, excitement and muscle tremor were observed in Group D after using Ketamine HCL. No side effects were found in Group A. In this experiment, no fatality was observed. (Table 2 )

\section{Discussion}

Effects of various anaesthetic and analgesic drugs in same individual were different during epidural analgesia. It occurred due to intrinsic anaesthetic potency of different anaesthetic agents. The physiochemical properties such as lipid solubility and protein binding appear to be primary determinant of intrinsic anaesthetic potency, Wildsmith et al. (1985). Among them, the lipid solubility of anaesthetic drugs demonstrates local anaesthetic activity. Local analgesic agents which are highly lipid soluable penetrate the nerve membrane more easily. The pronounced lipid solubility of anaesthetic agents causes low release of the drug from the lipid components of the spinal cord. These two aspects account for the change in the rate of access of anaesthetic with time to cerebrospinal fluid (CSF) and plasma and sustained concentrations in both fluids as well as redistribution of anaesthetic which in turn affect the duration of anaesthetic action, Perraz and Calvo (1991). The protein binding characteristic of anaesthetic agent's preliminary influence the duration of action of anaesthetic agents (Gissen et al., 1980). The induction time of anaesthesia was rapid in case of $2 \%$ lignocaine hydrochloride and ketamine hydrochloride. Anubhav et al. (2014) also found that the mean induction period of 
lidocaine hydrochloride was significantly shorter. On the contrary the onset was slower in case of $0.5 \%$ bupivacaine hydrochloride and lignocaine hydrochloride with adrenaline. Kinjavdekar and Patap (2002), Hall and Clarke (1989) observed that in epidural nerve block the onset of analgesia was slow with $0.5 \%$ bupivacaine hydrochloride and the onset was more rapid with $2 \%$ lignocaine hydrochloride, while Trim (1989) stated that lignocaine hydrochloride with adrenaline had a more rapid onset than bupivacaine hydrochloride. There are no available earlier reports to compare the findings of ketamine hydrochloride in term of onset of analgesia. The onset of epidural analgesia is generally governed by the rate of disappearance of anaesthetic solution from the site of injection i.e. absorption of the drugs through blood and lymphatic channel, duramater, epidural fat (Hall and Clarke, 1989). The most important of these are extradural venous plexuses and epidural fat. $2 \%$ lignocaine hydrochloride is rapidly absorbed from tissues and mucous membrane into blood (Hall and Clarke, 1989). Ketamine hydrochloride is highly lipid soluable drug. Its lipid soluable nonionized form is transferred rapidly to the CSF, nerve root and extradural root (Cousins and Mather, 1984). This physiochemical property might be responsible for the rapid onset of analgesia. During epidural analgesia, the peak time of analgesia was high with $0.5 \%$ bupivacaine hydrochloride whereas the peak time of analgesia was low with ketamine hydrochloride. There are no available earlier reports in term of peak time of analgesia. The time (the peak time of analgesia) at which maximum area was blocked and the progression of analgesia at peak time of anaesthesia were recorded to explain the extent of blockade of anaesthetic agents. During cranial epidural analgesia, highest area of desensitization at pick point in thigh region was recorded from the administration of bupivacaine hydrochloride and lowest from the administration of ketamine hydrochloride. Lignocaine hydrochloride and Bupivacaine hydrochloride also significantly produced higher desensitization area in inguinal region in cranial epidural analgesia. Both perineal region and tail was totally anaesthetized during epidural analgesia in all animals. K. Singh et al. (2007) stated that Bupivacaine produced complete analgesia of tail, perineum, inguinal and thigh regions in all animals. Whereas Ibrahim (2013) reported that lidocaine hydrochloride produced mild analgesia in flank, perineum, tail, low abdomen and hind limbs of sheep. Beltman et al. (2010) stated that the range of analgesia by epidural depended on dose of anesthetics. The duration of analgesia with $0.5 \%$ bupivacaine hydrochloride was longer during cranial epidural analgesia than $2 \%$ lignocaine hydrochloride. This observation corresponds with the previous findings (Trim, 1989; and Runa et al. 2008). Pathak et al. (2012) recorded the longest duration of complete analgesia with combination of bupivacaine and ketamine in buffalo calves. The protein binding characteristics of local analgesic agents influence the duration of action (Gissen et al., 1980). Agents such as bupivacaine, amethocaine and etidocaine are highly bound to proteins and display longest duration of anaesthesia. Besides this, rate of absorption, diffusibility of anaesthetic agents, speed of redistribution, all are responsible for duration of analgesia. If absorption is slow there will be an opportunity for more prolonged contact between solution and nerves, so that the intensity of spread is likely to be greater (Hall and Clarke, 1989). Lignocaine has intermediate duration of action. This observation was supported by Mpanduji and Ndossi (2013). The analgesia period by lidocaine hydrochloride was greater than lidocaine hydrochloride with adrenaline which was not supported by Rostami and Vesal (2012). The duration of anaesthesia with ketamine hydrochloride was lower during cranial epidural analgesia than $2 \%$ lignocaine hydrochloride. It is difficult to undergo any surgical intervention with ketamine hydrochloride due to its brief anaesthesia. Rapid redistribution of this drug from nerves to other tissues might be account for its short action (Lumb and Jones, 1984). Drowsiness and shivering were found during epidural analgesia with $0.5 \%$ bupivacaine hydrochloride. These finding are in agreement with the study reported by Laishley et al. (1988). These side effects were not observed in all animals. Straining and muscle tremor were found in some goats with the administration of ligno- caine hydrochloride with adrenaline. Tympany, excitement, muscle tremor and drowsiness were found during epidural analgesia with ketamine hydrochloride. DeRossi et al. (2010) found ketamine induced mild ataxia. Anubhav et al. (2014) observed occasional vocalization and struggling during cranial epidural analgesia with lidocaine hydrochloride.

\section{Conclusion}

In epidural analgesia $2 \%$ lignocaine hydrochloride and ketamine hydrochloride produced rapid onset and peak time of analgesia compared to $0.5 \%$ bupivacaine hydrochloride and $2 \%$ lignocaine hydrochloride with adrenaline. Bupivacaine hydrochloride produced delayed onset and peak time of analgesia. 0.5\% Bupivacaine hydrochloride produced the most extensive area of analgesia in hip region in epidural analgesia. During cranial epidural analgesia, $2 \%$ lignocaine hydrochloride and $0.5 \%$ bupivacaine hydrochloride also produced extensive area of analgesia in inguinal region. $0.5 \%$ bupivacaine hydrochloride produced prolonged duration of analgesia during cranial analgesia compared to other agents

\section{Acknowledgements}

I am ever grateful and indebted to the almighty God without whose grace I would have ever been able to pursue my higher studies in this field of science. I also express my deep sense of gratitude and immense indebtedness to my co-supervisor Professor Dr. Mirza Abul Hashim, Dept. Surgery and Obstetrics, Bangladesh Agricultural University, Mymensingh for his scholastic guidance, constant inspiration, constructive criticism, and successful completion of the research work and preparation of this manuscript.

\section{References}

[1] Anubhav K, MR Fazili, RA Shah, MH Bhat, FA Khan, SH Yaqoob, NA Naykoo and NA Ganai (2014). Comparison between lignocaine hydrochloride and ropivacaine hydrochloride as lumbosacral epidural anaesthetic agents in goats undergoing laparoscopy assisted embryo transfer. Mac Vet Rev, 37(2): i-ix.

[2] Beltman ME, Self I and Duane M (2010). The use of epidural in cattle. Irish Veterinary Journal, 63(1): 51-54.

[3] Booth NH (1988). Intrathecal and epidural anaesthesia. In: Veterinary pharmacology and Therapeutics. 6th edn. Iowa state University press. pp: 424.

[4] Brander GC, Pugh DM, Bywater RJ and Jenkins WL (1991). Veterinary Applied Pharmacology and Therapeutics. 5th edn, ISBN, Bailliere Tindall, London. pp: 110-114.

[5] Carpenter RE, Wilson DV and Evans AT (2004). Evaluation of intraperitoneal and incisional lidocaine or bupivacaine or analgesia following ovarihysterectomy in the dog. Anaesthesia and Analgesia, 31: 46-552. http://dx.doi.org/10.1111/j.1467-2995.2004.00137.x.

[6] Cousins MJ and Mather JE (1984). Intrathecal and epidural administration of opoid. Anaesthesiology, 61: 276-310. http://dx.doi.org/10.1097/00000542-198409000-00008.

[7] DeRossi R, Ruzzon RH, Verde-Selva AB and Bertoni RA (2010). Evaluation of segmental dorsolumber epidural analgesia with ketamine hydrochloride administered by use of nonstyletted multiple-port catheters via the caudal approach in cattle. Am j Vet Res, 71(1): 17-23. http://dx.doi.org/10.2460/ajvr.71.1.17.

[8] Dripps RD, Echenhoff JE and Vandem LD (1988). Introduction to anaesthesia. In: The principles of safe practice. 7 th edn, W.B. Saunders Co. Philadelphia pp: 233-235.

[9] Eugene PS and Nicholas HB (1995). Local anaesthetics. In: Veterinary Pharmacology and Therapeutics. Iowa State University Press. pp: 271-358.

[10] Gissen AJ, Covino BG and Gregvs J (1980). Differential sensitivity of mammalian nerve fibres to anaesthetic agents. Anaesthesiology, 53: 467-474. http://dx.doi.org/10.1097/00000542-198012000-00006.

[11]Hall LW and Clarke KW (1989). Veterinary Anaesthesia. 8th edn. Bailliere Tindall, London. 
[12]Hasim MA and Hossain MA 91989). Effect of starvation and positioning on gastroesophageal reflux in anaesthetized goat during chloride hydratemagnisium sulphate anaesthesia. Bangladesh Journal of Scientific and Industrial Research, 24: 62-69.

[13]Ibrahim MN (2013). Behavioral and analgesic effect of acepromazine maleate, lidocaine hydrochloride alone or in combination of them in lumbosacral epidural injection in sheep. The Iraqi Journal of Veterinary Medicine, 37(2): 232-236.

[14]Kinjavdekar P and Partap K (2002). Comparison of Ketamine and xylazine for lumbo-sacral epidural analgesia in buffalo calves. Indian Journal of Veterinary Surgery, 21(2): 117.

[15]K Singh, P Kinjavdekar, Amarpal, HP Aithal, A Gopinathan, GR Singh, AM Pawde and K Prata (2007). Comparison of the analgesic, clinicophysiological and hematobiochemical effects of epidural bupivacaine in healthy and uremic goats. Small Ruminant Research, 71(13): 13-20. http://dx.doi.org/10.1016/j.smallrumres.2006.02.009.

[16]Laishley RS, Morgan and Reynolds F (1988). Effect of Bupivacaine on extradural anaesthesia. British Journal of Anaesthesia, 60: 180-186. http://dx.doi.org/10.1093/bja/60.2.180.

[17] Lumb WV and Jones EW (1984). Local anaesthesia. In: Veterinary Anaesthesia. Edited by JC Thurmon, WJ Tranquilli and GJ Benson. Lippincott, Williams and Wilkins, Philadelphia, pp: 330-336.

[18]Mpanduji DG and Ndossi DG (2013). Comparison of analgesia and cardio-pulmonary effects of epidural injection of pathedine and lidocaine in small East African goats. Res. Opin. Anim. Vet. Sci, 3(2): 30-34.

[19]Perraz, JL and Calvo MB (1991). Pharmacokinetics and distribution of ketamine after extradural administration to dogs. British Journal of Anaesthesia, 67: 310-316. http://dx.doi.org/10.1093/bja/67.3.310.

[20]R Pathak, K Pratap, Amarpal, P Kinjavdekar, HP Aithal and Pankaj (2012). Comparison of bupivacaine, xylazine and buprenorphine with ketamine combination for spinal analgesia in buffalo calves. Vet world, 5(12): 754-761.

[21] Rostami M and Vesal N (2012). The effects of adding epinephrine or xylazine to lidocaine solution for lumbosacral epidural analgesia in fat-tailed sheep. J S Afr Vet Assoc, 83(1): 1-7 http://dx.doi.org/10.4102/jsava.v83i1.1.

[22]RA Runa, MA Hashim, MA Hossain, AAM Bhuyan and MS Alam (2008). Comparative efficacy of analgesic and anaesthetic drugs for high epidural analgesia in Black Bengal goats. Bang J Vet Med, 6(1): 103-106.

[23] Trim CM (1989). Epidural analgesia with $0.75 \%$ Bupivacaine for laparotomy in goats. Journal of American Veterinary Medical Association, 194(9): 1292-1296.

[24]Wildsmith JAW, Gisen AJ, Gregus J and Covino BG (1985). Differential nerve blocking activity of amino-ester local anaesthetics. British Journal of Anaesthesia, 57: 612-620. http://dx.doi.org/10.1093/bja/57.6.612. 